\title{
Making Choices While Smelling, Tasting, and Listening: The Role of Sensory (Dis)similarity When Sequentially Sampling Products
}

\author{
Dipayan Biswas \\ University of South Florida, dbiswas@usf.edu \\ Lauren Labrecque \\ Loyola University Chicago, Ilabrecque@luc.edu \\ Donald R. Lehmann \\ Columbia University, drl2@columbia.edu \\ Ereni Markos \\ Suffolk University, emarkos@suffolk.edu
}

Follow this and additional works at: https://ecommons.luc.edu/business_facpubs

Part of the Marketing Commons

\section{Recommended Citation}

Biswas, Dipayan; Labrecque, Lauren; Lehmann, Donald R.; and Markos, Ereni. Making Choices While Smelling, Tasting, and Listening: The Role of Sensory (Dis)similarity When Sequentially Sampling Products. Journal of Marketing, 78, : 112-126, 2014. Retrieved from Loyola eCommons, School of Business: Faculty Publications and Other Works, http://dx.doi.org/10.1509/jm.12.0325

This Article is brought to you for free and open access by the Faculty Publications and Other Works by Department at Loyola eCommons. It has been accepted for inclusion in School of Business: Faculty Publications and Other Works by an authorized administrator of Loyola eCommons. For more information, please contact ecommons@luc.edu.

\section{c) (i) $\odot$}

This work is licensed under a Creative Commons Attribution-Noncommercial-No Derivative Works 3.0 License. (C) American Marketing Association, 2014 


\section{Making Choices While Smelling, Tasting, and Listening: The Role of Sensory (Dis)similarity When Sequentially Sampling Products}

Marketers are increasingly allowing consumers to sample sensory-rich experiential products before making purchase decisions. The results of seven experimental studies (two conducted in field settings, three conducted in a laboratory, and two conducted online) demonstrate that the order in which consumers sample products and the level of (dis)similarity between the sensory cues of the products influence choices. In the absence of any moderators, when sampling a sequence of sensory-rich experiential products (e.g., fragrances, chocolates, flavored beverages, music) with similar sensory cues (e.g., smell, taste, color, sound), consumers prefer the first product in the sequence. However, when sampling a sequence of products with dissimilar sensory cues, consumers prefer the last product. These findings (1) contribute to a better understanding of the role of sequential sensory cues on consumer choice formation, (2) have implications for effects related to sensory habituation and sensory trace fading, and (3) help resolve apparent inconsistencies in prior research on order effects in the context of choices for sequentially sampled experiential products.

Keywords: sensory cues, sequential and order effects, sampling, sensory habituation and traces, retail displays

$\mathbf{M}$ anagers are increasingly focusing on experiential and sensory aspects when formulating marketing strategies (Wyrley-Birch 2013). Experiential products, such as foods, beverages, and fragrances, tend to be rich in sensory cues, such as taste, smell, and color (Krishna 2012; Troye and Supphellen 2012). As a result, marketers for these types of products often manipulate sensory inputs to enhance the overall product experience. For example, although Unilever sells both Axe deodorant and Dove deodorant, the company has engineered the sound made by Axe spray to be different from the sound made by Dove spray (Hall 2013). In addition, for sensory-rich products (e.g., fragrances, food/beverages, music), marketers are often able to facilitate sampling opportunities for consumers before they make purchase decisions (Biswas, Grewal, and Roggeveen 2010; Nowlis and Shiv 2005; Shiv and Nowlis 2004; Wadhwa, Shiv, and Nowlis 2008). Indeed, companies and retailers have been increasingly eager to provide free samples of food/beverage items at supermarkets (Notte 2011) and offer fragrance samples on scented

Dipayan Biswas is Associate Professor of Marketing, University of South Florida (e-mail: dbiswas@usf.edu). Lauren I. Labrecque is Assistant Professor of Marketing, Loyola University Chicago (e-mail: llabrecque@luc. edu). Donald R. Lehmann is George E. Warren Professor of Business, Columbia University (e-mail: drl2 @ columbia.edu). Ereni Markos is Assistant Professor of Marketing, Suffolk University (e-mail: emarkos@suffolk. edu). The authors thank Adwait Khare, Antonia Mantonakis, Elizabeth Miller, Courtney Szocs, and the anonymous JM reviewers for helpful comments. Stephen Nowlis served as area editor for this article. strips at department stores and in magazines (Thau 2012). The increased availability of sampling opportunities is largely driven by companies that consider providing free samples a more powerful and cheaper alternative to traditional forms of advertising (Tuttle 2011). Thus, according to some estimates, the food and beverage industry alone spends more than a billion dollars annually on free product samples (Horovitz 2011). Similarly, companies also spend tens of millions of dollars on fragrance strips (also called "scent strips"). Scent strips have been commercially used since the late 1970s, and within ten years, companies were spending more than $\$ 40$ million on scent strip samples (Malcolm 1988). Currently, retailers use scent strip samples aggressively as a major marketing tool (Louis 2011).

Despite the existence of such widespread sampling practices for sensory-rich products, it is unclear whether and how the order in which consumers sample products with similar or dissimilar sensory cues influences their choices. This is especially relevant because consumers are often able to sample multiple items before purchase (Biswas, Grewal, and Roggeveen 2010; Louis 2011). Moreover, although there is a rich emerging literature stream in the domain of sensory marketing (for a detailed review, see Krishna 2012), no study has examined the order effects of sampling a sequence of products with similar versus dissimilar sensory cues on product preferences or choices. Because determining preferences from a set of options is an important aspect of consumer decision making (Biswas, Zhao, and Lehmann 2011; Hoegg and Alba 2007), examining how consumer product preferences and choices are 
determined by a sequence of products with similar versus dissimilar sensory cues has both theoretical and practical implications. In this regard, the findings of our research contribute to a better understanding of the role of sequential sensory cues on consumer choice formation.

As an illustrative example, suppose that a consumer samples two fragrances using scent strips. Would the consumer's final preference be influenced by the order in which she sampled the fragrances? We posit that her preference would depend on the level of similarity between the sensory aspects of the sampled products. Specifically, we propose that when two sequentially sampled products have similar sensory cues (e.g., olfactory, visual), there will be greater preference for the product sampled first. In contrast, when the sequentially sampled products have dissimilar sensory cues, there will be greater preference for the product sampled last. We also demonstrate that although this pattern of results holds for different types of sensory cues, it does not hold for nonsensory cues (e.g., brand name). The present research is the first to examine how (dis)similarity of sensory cues for a sequence of sampled products can influence choice.

Although we are not aware of any research on the role of sensory (dis)similarity of sequentially sampled products influencing choices, there is a rich literature on order effects in general (Biswas, Biswas, and Chatterjee 2009; GürhanCanli 2003). Researchers have typically observed two types of order effects: primacy effects, whereby the stimulus encountered earlier in the sequence is more influential and/or better recalled, and recency effects, whereby the stimulus encountered later in the sequence is more influential and/or better recalled (Gürhan-Canli 2003).

Prior studies on order effects have predominantly been conducted using nonsensory product cues and have had a judgment rather than a choice focus. In contrast, limited research has examined order effects on choices/preferences after sampling (i.e., actually consuming) a sequence of sensory-rich products, with Biswas, Grewal, and Roggeveen (2010), Dean (1980), Mantonakis et al. (2009), and O'Brien and Ellsworth (2012) among the exceptions. Notably, these four studies report different results pertaining to order effects of sampling sequential products. For example, Dean (1980) had participants sample a sequence of two beverages and reports primacy effects such that the majority of participants preferred the beverage they sampled sequentially first. Mantonakis et al. (2009) examined the order effects of sequential sampling of wines and also report primacy effects, especially for shorter sequences, whereby participants preferred the wine sampled first. In contrast, Biswas, Grewal, and Roggeveen (2010) report recency effects, whereby participants indicated stronger preference for the product (e.g., beverage/music) sampled sequentially last. More recently, O'Brien and Ellsworth (2012) had participants sample a sequence of chocolates and also report recency effects such that the chocolate sampled last was most favorably evaluated. Our research findings should help resolve the apparent inconsistency of these prior studies, as we discuss in detail in a subsequent section.
In summary, we examine order effects of sampling a sequence of products with similar versus dissimilar sensory cues on product preference. We use a variety of products that are rich in sensory cues, including fragrances, food products (e.g., beverages, chocolates), and music clips. We test our hypotheses in seven diverse experimental studies (two conducted in field settings, three conducted in a laboratory, and two conducted online [one with participants from a national online panel and another with university students]). Study 1a, a field experiment conducted at a restaurant, examines how sampling a sequence of beverages with either similar or dissimilar sensory cues (taste and color) influences product preference. The results show that when the products have similar sensory cues, there are primacy effects, but when the products have dissimilar sensory cues, there are recency effects. Study $1 \mathrm{~b}$, another field study, replicates the findings of Study 1a using a different set of products (chocolate samples). Study 1c shows that the recency effects observed for dissimilar sensory cues hold regardless of whether the sensory cues vary on one dimension or multiple dimensions. Study 2 examines whether the order effects of sampling products with similar versus dissimilar cues holds in the case of nonsensory cues. Study 3 provides evidence in support of our theoretical claims by examining the effects of sensory interruption. Specifically, participants sampled (i.e., sniffed) a sequence of two scent strips as well as either a cup of coffee beans (presence of sensory interruption) or a cup of cotton balls (absence of sensory interruption) between smelling the scent strip samples. Study $4 \mathrm{a}$ enhances the generalizability of the previous studies by increasing the number of products sampled. More importantly, the results of Study 4 a provide additional evidence regarding our theoretical claims. Finally, Study $4 b$ replicates the key findings of our previous studies when consumers have the option of being indifferent when making choices.

\section{Theoretical Background}

As mentioned previously, most prior research studies on order effects have been conducted in the context of nonsensory cues and product attributes - such as information on price discounts, warranties, and brand reputation-and focused on judgment rather than on choice/preference. These studies have typically found primacy effects, in terms of better recall of earlier pieces of data, which have often been explained by the role of information rehearsal in working memory (Biswas, Biswas, and Chatterjee 2009; Büyükkurt 1986; Oberauer and Lewandowsky 2008).

The process is likely to be significantly different for sensory cues, such as odor or taste, mainly because sensory cues are typically ambiguous and therefore difficult to encode or retrieve (Shapiro and Spence 2002). We propose that when encountering sensory cues while evaluating a sequence of products, two opposing forces influence the order effects of sampling the products. First, from the perspective of sensory traces, there will be an inherent tendency to prefer the item sampled sequentially last. That is, experiences associated with a sensory cue tend to form traces in the brain (Graziano and Sigman 2008; Yu, Pono- 
marev, and Davis 2004). With multiple sensory cues, the traces associated with a sequentially earlier sensory stimulus tend to fade (i.e., decay) when subsequent sensory stimuli are experienced (Biswas, Grewal, and Roggeveen 2010; Sergent et al. 2013). This phenomenon occurs primarily because each sensory cue is processed in sensory-specific areas of the brain (Driver and Noesselt 2008); therefore, over time or with additional sensory cue inputs, the traces associated with the earlier sensory cues fade (Engel and Andrieux 2010; Graziano and Sigman 2008; Zylberberg et al. 2009). As a result, this stream of research has suggested that recency effects will be present, resulting in preference for the last sampled product in a sequence (Stecker and Hafter 2009). For example, Biswas, Grewal, and Roggeveen (2010) find that when sampling a sequence of experiential products, consumers have more vivid recall of the experience associated with the item sampled last.

In contrast, research in the domain of sensory habituation has suggested that people will prefer the first sensoryrich product in a sequence (i.e., primacy effects) because there is likely to be decreased sensitivity to, or liking of, repeated exposure to a stimulus (Epstein et al. 2009; Morewedge, Huh, and Vosgerau 2010). Sensory habituation has been explained from both physiological and neurological perspectives. Specifically, because a sensory cue elicits physiological and neurological responses, repeated applications of the sensory cue will result in decreasing responses; this overall process is conceptually how habituation is defined (Thompson 2009). As a result, for example, the first chocolate is usually considered more desirable than subsequent ones (e.g., Morewedge, Huh, and Vosgerau 2010). Note that although sensory habituation and sensory-specific satiety would make similar predictions in many cases (including in the contexts of our studies) and are sometimes used interchangeably in the literature (Epstein et al. 2009), they are different constructs with clear distinctions between them. Sensory habituation refers to decreased sensitivity or the phenomenon of becoming used to a certain type of sensory stimulus, whereas sensory-specific satiety is reduced pleasantness often associated with, for example, repeated orosensory exposure to a particular food or beverage (Havermans, Siep, and Jansen 2010; Inman 2001). In other words, sensory-specific satiety is unidirectional, whereas sensory habituation need not be unidirectional. For example, a loud noise will initially evoke a startled response, but repeated exposure to this noise will cause sensory habituation to this stimulus. Sensory-specific satiety, however, has no significant role in this scenario.

In summary, the theoretical model related to sensory trace fading effects would predict recency effects (i.e., preference for product sampled last in the sequence), whereas sensory habituation theory would predict primacy effects (i.e., preference for product sampled first in the sequence). Which one of these theoretical effects will be dominant when sampling a sequence of sensory-rich experiential products? We propose that the answer depends on the level of (dis)similarity between the sensory cues encountered in the sequence. When the encountered sensory cues are similar, there is likely to be a greater effect of sensory habitua- tion (or satiety) because repeated exposure to the same or similar sensory stimuli enhances sensory habituation (Avena and Gold 2011). As a result, when sampling a sequence of products with similar sensory cues, sensory habituation will cause primacy effects in terms of preference for the first sampled product. In contrast, when the sequentially encountered sensory cues are dissimilar, the effect of sensory habituation is weakened (Epstein et al. 2009). As a result, there will be a more dominating influence of sensory trace fading effects. Therefore, when sampling a sequence of products with dissimilar sensory cues, recency effects, in terms of preference for the last sampled product, will be present because earlier sensory traces will have faded. Formally stated:

$\mathrm{H}_{1}$ : When sampling a sequence of products with similar sensory cues, consumers will prefer the first product (primacy effect). However, when sampling a sequence of products with dissimilar sensory cues, consumers will prefer the last product (recency effect).

\section{Study 1a: Method}

\section{Design, Participants, and Procedure}

Study 1a is a field experiment conducted at a casual dining restaurant in the northeastern United States, in collaboration with the restaurant management. The experiment had a between-subjects design with two products from the same category (flavored beverages) but with either similar or dissimilar sensory cues. Forty-four restaurant patrons $\left(\mathbf{M}_{\text {age }}=\right.$ 42 years; $52 \%$ female) participated in this field experiment in exchange for complimentary beverages (i.e., in addition to the beverages in the experiment, participants received a coupon for a free beverage from the regular menu).

The flavored beverages were prepared by mixing commercially available water flavor enhancers. In the similar sensory cue conditions, the two beverage mixes had either eight or six squirts of lemonade flavor added to a half-gallon of purified water. In the dissimilar sensory cue conditions, the two beverage mixes had either eight squirts of lemonade flavor or six squirts of strawberry watermelon flavor added to a half-gallon of purified water. As a result, in the similar sensory cue condition, the beverages (i.e., flavored water) were almost identical in taste and color, whereas in the dissimilar sensory cue condition, the beverages differed in both taste and color. We conducted a pretest $(n=31)$ to ensure that the beverages were equally desirable in independent evaluations. Participants sampled multiple beverages and also undertook several unrelated tasks between each beverage sampling to ensure that there were no order or carryover effects. Participants indicated their taste perceptions immediately after sampling each beverage (rather than at the end of a sequence, as in the main studies). Participants indicated their taste perception on a seven-point scale, as in prior studies (e.g., Elder and Krishna 2010; 1 = "very bad taste," and $7=$ "very good taste"). The results of the pretest showed that the eight-squirt lemonade, the sixsquirt lemonade, and the six-squirt strawberry watermelon mixes had taste ratings of $3.79,3.48$, and 3.57 , respectively, 
and these values are not significantly different from one another (all $p$-values $>.30$ ).

In the main experiment, a researcher randomly approached restaurant patrons and asked them to participate in the study in exchange for a free drink coupon. The data collection spanned several business hours, resulting in a broad sampling of customers. We created a cover story suggesting that the restaurant was considering including additional beverage options on its menu and was looking for customer feedback. Because the restaurant already had several beverage options (including nonalcoholic cocktails) on its menu, we deemed it a credible cover story.

The restaurant patrons were then randomly offered two beverage samples that were either similar to or different from each other on the sensory cues of taste and color. The survey instructed participants to sample the two beverages (4 ounces each) sequentially. We randomized the order in which participants sampled the beverages to avoid order effects related to a particular beverage. Participants responded to the key dependent variable of product preference ("Between the two beverages that you sampled, which one did you like more?").

\section{Results}

Overall, consumers chose the beverage sampled sequentially last to a greater extent when the sensory cues were dissimilar (vs. similar) and chose the first beverage to a greater extent when the sensory cues were similar (vs. dissimilar $)\left(\chi^{2}=9.21, p<.01\right)$. Specifically, consistent with $\mathrm{H}_{1}$, when sampling the two sequential beverages with similar sensory cues, most participants preferred the first beverage $\left(\right.$ Proportion $_{\text {first }}=76.19 \%$ vs. Proportion $_{\text {last }}=23.81 \%$; $\left.\chi^{2}=5.76, p<.05\right)$, but when sampling the two beverages with dissimilar sensory cues, most participants preferred the last beverage $\left(\right.$ Proportion $_{\text {first }}=30.43 \%$ vs. Proportion $_{\text {last }}=$ $\left.69.57 \% ; \chi^{2}=3.52, p<.07\right)$.

\section{Discussion}

The results of Study 1a show that when sampling a sequence of two products with similar sensory cues, consumers prefer the first sampled product; however, when the products have dissimilar sensory cues, consumers prefer the last sampled product in the sequence. Study $1 \mathrm{~b}$, another field experiment, replicates these findings with a different product category.

\section{Study 1b: Method}

\section{Design, Participants, and Procedure}

Study $1 \mathrm{~b}$ has a similar design and procedure as Study 1a. Study $1 \mathrm{~b}$ is also a field experiment conducted at a casual dining restaurant in the northeastern United States, in collaboration with the restaurant management, but we used chocolates instead of beverages. In addition, whereas the products in the sensory-dissimilar condition in Study 1a differed on the sensory aspects of taste and color, in Study 1b, the products were identical in terms of visual appearance and differed only on the sensory aspect of taste. To avoid familiarity biases, the chocolates used as products in this experiment were obtained from a specialty store located in a different town from the restaurant. We determined the chocolate selections using a pretest $(n=16)$. In the pretest, participants sampled and rated the taste of several types of chocolate (seven-point scale; 1 = "very bad taste," and 7 = "very good taste") (see, e.g., Elder and Krishna 2010). Participants indicated their taste perceptions immediately after each sampling (rather than at the end of the sequence, as in the main studies) and completed filler tasks between each chocolate sampling to avoid potential carryover effects. We chose two varieties of milk chocolates for the similar sensory cue condition on the basis of the pretest results $(\mathrm{M}=$ 4.25 vs. $\mathrm{M}=4.31 ; \mathrm{F}(1,15)=.03, p=.88)$. For the dissimilar sensory cue condition, we chose one of these milk chocolates and a raspberry-flavored chocolate $(M=4.25$ vs. $\mathrm{M}=4.06 ; \mathrm{F}(1,15)=.18, p=.68)$.

In the main experiment, as in Study 1a, we created a cover story suggesting that the restaurant was considering adding chocolates to their menu and wanted customer feedback. The restaurant already offers customers chocolatebased options, including chocolate beverages and various types of cakes and cookies; therefore, we considered this cover story credible. Fifty-one restaurant patrons $\left(\mathrm{M}_{\mathrm{age}}=\right.$ 38 years, 26\% female) participated in the experiment in exchange for a free drink and complimentary chocolates.

We randomly offered restaurant patrons two bite-sized chocolate samples that were either similar to or different from each other in terms of taste. The survey instructed participants to sample the two chocolates sequentially. The order of the chocolates was counterbalanced across conditions. Participants responded to a series of questions, including the key dependent variable of product preference ("Between the two chocolates that you sampled, which one did you like more?") and a manipulation check question regarding the extent to which the sampled chocolates were similar to or different from each other in terms of taste $(1=$ "extremely similar," and 7 = "extremely different").

\section{Results}

Manipulation check. Our results were consistent with the manipulations. Participants in the sensory-dissimilar (vs. sensory-similar) condition perceived greater difference between the chocolates $\left(M_{\text {similar }}=3.04\right.$ vs. $M_{\text {dissimilar }}=6.0$; $\mathrm{F}(1,48)=56.52, p<.01)$.

Main test. Consumers chose the chocolate sampled sequentially last to a greater extent when the sensory cues were dissimilar (vs. similar) and chose the first chocolate to a greater extent when the sensory cues were similar (vs. dissimilar) $\left(\chi^{2}=7.07, p<.01\right)$. Specifically, consistent with $\mathrm{H}_{1}$ and the findings of Study 1a, when sampling the two sequential chocolates with similar sensory cues, a greater proportion of participants preferred the first chocolate (Proportion $_{\text {first }}=69.23 \%$ vs. Proportion last $=30.77 \% ; \chi^{2}=3.85$, $p<.05)$, but when sampling the two chocolates with dissimilar sensory cues, a higher proportion of participants preferred the last chocolate (Proportion $_{\text {first }}=32.0 \%$ vs. Proportion $\left._{\text {last }}=68.0 \% ; \chi^{2}=3.24, p<.08\right)$. 


\section{Discussion}

Study $1 \mathrm{~b}$ replicates the findings of Study 1a and shows that when sampling a sequence of two chocolates with similar sensory cues, consumers prefer the first sampled product; however, they prefer the last sampled product in the sequence when the products have dissimilar sensory cues. Next, Study 1c examines whether dissimilarities on multiple sensory cues might have different effects than dissimilarity on one sensory cue.

\section{Study 1c: Effects of Single Versus Multiple Sensory Cues}

Study 1a examined the effects of varying multiple sensory cues (color and taste), and Study $1 \mathrm{~b}$ examined the effects of varying a single sensory cue (taste). However, these studies did not examine the effects of varying a single sensory cue versus multiple sensory cues, which is a relevant factor for products in many real-world contexts. Thus, Study 1c examines whether the effects of sensory dissimilarity change when either one or two sensory cues are varied. In addition, whereas Studies 1a and $1 \mathrm{~b}$ used food and beverage products, Study 1c uses a nonfood product (scented paper strips, similar to those provided at department stores to sample fragrances).

\section{Design, Participants, and Procedure}

The key sensory cues in Study 1c involved the scent of the fragrance and the color of the testing strips. Participants were given two scented paper strips and instructed to sniff them sequentially. The study was a between-subjects design experiment with four manipulated conditions: the two scented strips had (1) similar colors and similar scents, (2) similar colors but dissimilar scents, (3) dissimilar colors but similar scents, or (4) dissimilar colors and dissimilar scents. We counterbalanced the order in which participants sampled each scent strip to prevent the specific scent strip serial position from influencing the overall results. One hundred sixty-three students from a major U.S. university $\left(\mathrm{M}_{\text {age }}=\right.$ 23 years; $55 \%$ female) participated in the experiment in exchange for course credit.

Two independent pretests were conducted to determine the appropriate colors and scents. In the first pretest $(\mathrm{n}=$ 16), participants were asked to evaluate five colors of scent strips in terms of liking and desirability on a seven-point scale ( 1 = "low," and 7 = "high"). Participants provided their evaluations immediately after sampling each of the strips (rather than at the end of a sequence, as in the main studies). We chose blue- and green-colored scent strips because these colors had equally favorable evaluations in the pretest $(\mathrm{M}=4.91 \mathrm{vs} . \mathrm{M}=4.88 ; \mathrm{F}(1,15)=.01, p=.93)$. We conducted a second pretest $(n=18)$ to determine the appropriate scents to be used in the main experiment. Participants evaluated the smells of multiple scents (on white testing strips) on a seven-point scale ( 1 = "very bad," and 7 = "very good"). There were filler tasks between each sampling, and participants indicated their evaluation immediately after each sampling rather than at the end of a sequence. Participants rated lavender and jasmine scents as equally favorable in the pretest $(\mathrm{M}=4.39$ vs. $\mathrm{M}=4.28$; $\mathrm{F}(1,17)=.16, p=.69)$. Therefore, for the dissimilar sensory cue condition, we used lavender and jasmine scents, whereas for the similar sensory cue condition, we used two variations of lavender scent (which differed slightly in terms of intensity).

In the main study, as in Study 1b, the key dependent variable was product preference ("Between the two scenttesting strips that you sniffed, which one did you like more?"). As a manipulation check, participants indicated their perceived (dis)similarity between the two sampled products (seven-point scale; 1 = "extremely similar," and 7 = "extremely different").

\section{Results}

Manipulation check. Compared with when both the color and the scent were similar $(\mathrm{M}=2.74)$, participants perceived greater dissimilarity when only the color of the strip was varied $(\mathrm{M}=3.84 ; \mathrm{t}(82)=3.21, p<.01)$, when only the scent of the fragrance was varied $(\mathrm{M}=3.89 ; \mathrm{t}(89)=$ $3.15, p<.01)$, and when both the color and scent were varied $(\mathrm{M}=4.15 ; \mathrm{t}(78)=3.96, p<.01)$. There were no differences in perceived dissimilarity between the latter three conditions (all $p$-values $>.30$ ).

Main test. There were no effects of counterbalancing for each of the four manipulated conditions (all $\chi^{2}$ values $<.3$ and all $p$-values $>.60$ ). As we hypothesized, when sequentially evaluating two scent strips with sensory similarity, most participants preferred the fragrance associated with the first scent strip in the sequence (Proportion $_{\text {first }}=71.74 \%$ vs. Proportion $\left._{\text {last }}=28.26 \% ; \chi^{2}=8.70, p<.01\right)$. However, most participants preferred the fragrance of the last scent strip in the sequence when only the color of the strip varied Proportion $_{\text {first }}=34.21 \%$ vs. Proportion last $=65.79 \% ; \chi^{2}=$ $3.79, p<.06)$, when only the scent varied $\left(\right.$ Proportion $_{\text {first }}=$ $33.33 \%$ vs. Proportion last $\left.=66.67 \% ; \chi^{2}=5.0, p<.05\right)$, and when both the color and scent varied Proportion $_{\text {first }}=$ $35.29 \%$ vs. Proportion $\left.{ }_{\text {last }}=64.71 \% ; \chi^{2}=2.94, p<.10\right)$. In essence, the preference pattern for the similar sensory cue condition differed from that of the dissimilar sensory cue conditions - when only the strip color was different $\left(\chi^{2}=\right.$ $11.83, p<.01)$, when only the scent was different $\left(\chi^{2}=\right.$ $13.46, p<.01)$, and when both the strip color and fragrance scent were different $\left(\chi^{2}=10.55, p<.01\right)$. There were no significant differences in preferences across the latter three conditions (all $p$-values $>.80$ ).

\section{Discussion}

The results of Study 1c highlight the robustness of our previous studies' findings in the context of a nonfood product (scent sampling strips). As in Studies 1a and 1b, there were primacy effects when the sequentially sampled products had sensory similarity and recency effects when the sequentially sampled products had sensory dissimilarity, and this recency effect was of equal magnitude when the dissimilarity was for one or two sensory cues. Notably, changing the strip's color influenced scent preferences even though the strip was not directly related to the fragrance. Such a finding has implications for emerging research on cross-modal 
sensory effects, whereby visual cues can influence olfactory perceptions (Hanson-Vaux, Crisinel, and Spence 2013). Next, Study 2 examines whether the effects of cue (dis)similarity extend to nonsensory cues.

\section{Study 2: Sensory Versus Nonsensory Cues}

Prior research has demonstrated that people process sensory and nonsensory cues differently. Compared with nonsensory cues, sensory cues are typically ambiguous and more difficult to encode and retrieve (Shapiro and Spence 2002). As a result, for example, satiety, which is relevant for sensory cues, has less relevance for nonsensory cues (Inman 2001). We theorize that when evaluating a sequence of sensoryrich products, the effects of sensory habituation (Morewedge, Huh, and Vosgerau 2010) will lead to primacy effects (preference for first sampled product) when the sampled products have similar sensory cues, whereas effects related to sensory trace fading (Zylberberg et al. 2009) will lead to recency effects (preference for last sampled product) when the sampled products have dissimilar sensory cues. If our theorization holds, this pattern of effects should occur for sensory but not nonsensory cues (see, e.g., Inman 2001) because effects of sensory habituation and sensory trace fading apply only to sensory cues.

As we noted previously, most prior studies on sequences or order effects of nonsensory cues (e.g., brand name, price discounts, warranty information) have focused on such dependent variables as judgments and recall instead of preference. These studies have typically found assimilation versus contrast effects when people encounter nonsensory cues that are similar versus dissimilar (see, e.g., Lynch, Chakravarti, and Mitra 1991; Meyers-Levy and Sternthal 1993; Zhu and Meyers-Levy 2009). Although scholars have applied assimilation and contrast effects in the context of calorie estimations (Chernev 2011), categorization (Bless and Schwarz 2010; Schwarz and Bless 1992), and digital bundling (Elberse 2010), none of these studies are in the context of actual experiential consumption of sensory-rich products. We predict that the effects related to sensory habituation and sensory trace fading will hold in the context of experiential sensory cues but not for nonsensory cues. Therefore, we propose that the effects observed in Studies 1a-c will hold for (dis)similarity of sensory cues regardless of the accompanying nonsensory cue's (dis)similarity.

$\mathrm{H}_{2}$ : When sampling a sequence of products, consumers will prefer the first product (primacy effect) when the sampled products have similar sensory cues and the last product (recency effect) when the sampled products have dissimilar sensory cues, regardless of whether the accompanying nonsensory cues are similar or dissimilar.

\section{Design, Participants, and Procedure}

We tested $\mathrm{H}_{2}$ with a 2 (sensory cues: similar vs. dissimilar) $\times$ 2 (nonsensory cues: similar vs. dissimilar) between-subjects design experiment. One hundred seventy-five students from a major U.S. university ( $M_{\text {age }}=24$ years; $50 \%$ female) participated in exchange for complimentary beverages and course credit. The same beverage sets used in Study 1a were used in Study 2, in addition to the same manipulation for similar versus dissimilar sensory cues. Consistent with prior studies (e.g., Inman 2001), brand name was the nonsensory cue, which we manipulated by telling participants that both the beverages were of either the same brand (similar nonsensory cues condition) or different brands (dissimilar nonsensory cues condition). We did not use actual brand names because we wanted to avoid familiarity bias and affective sensory reactions to actual brand names (Keller and Lehmann 2006). We instructed participants to sample the two beverages (4 ounces each) sequentially, as in Study 1. We measured product preference, the key dependent variable in Study 2, the same way as in Studies 1a-c.

\section{Results}

We counterbalanced the beverages to ensure that the serial position of a particular beverage did not influence the results. There were no effects of the counterbalancing on product preference across the four experimental conditions (all $\chi^{2}$ values $<.9$, and all $p$-values $>.35$ ).

We did not expect an interaction effect, because we did not expect the nonsensory cue of brand name to have any effect on the relationship between sensory cue (dis)similarity and product preference; that is, the effects of sensory (dis)similarity on product preference should be the same regardless of whether the brand names were similar or dissimilar. Consistent with such an expectation, the effects of a 2 (sensory cues: similar vs. dissimilar) $\times 2$ (nonsensory cues: similar vs. dissimilar) logistic regression on product preference showed a lack of an interaction effect (Wald $\chi^{2}=$ $.01, p=.92)$, which follow-up tests also highlighted. When the nonsensory cues were similar, with similar sensory cues, more consumers preferred the first beverage (Proportion $_{\text {first }}=64 \%$ vs. Proportion last $\left.=36 \% ; \chi^{2}=3.92, p<.05\right)$, and with dissimilar sensory cues, more consumers preferred the last beverage $\left(\right.$ Proportion $_{\text {first }}=33.33 \%$ vs. Proportion Past $_{\text {las }}$ $\left.=66.67 \% ; \chi^{2}=4.67, p<.05\right)$. When the nonsensory cues were dissimilar, the pattern of results was the same; that is, with similar sensory cues, more consumers preferred the first beverage (Proportion $_{\text {first }}=64.86 \%$ vs. Proportion $_{\text {last }}=$ $35.14 \% ; \chi^{2}=3.27, p<.08$ ), and with dissimilar sensory cues, more consumers preferred the last beverage (Proportion $_{\text {first }}=31.82 \%$ vs. Proportion last $=68.18 \% ; \chi^{2}=5.82, p<$ $.05)$. Figure 1 graphically presents these results.

Follow-up tests also show that overall, when sampling two beverages with similar sensory cues, participants preferred the first beverage in the sequence $\left(\right.$ Proportion $_{\text {first }}=$ $64.37 \%$ vs. Proportion last $=35.63 \% ; \chi^{2}=7.18, p<.01$ ), implying primacy effects. However, when sampling two beverages with dissimilar sensory cues, more participants preferred the last beverage in the sequence $\left(\right.$ Proportion $_{\text {first }}=$ $32.56 \%$ vs. Proportion $\left.{ }_{\text {last }}=67.44 \% ; \chi^{2}=10.47, p<.01\right)$, implying a recency effect. Overall, the preference pattern differed for similar versus dissimilar sensory cues $\left(\chi^{2}=17.52\right.$, $p<.01)$. In contrast, there were no such effects for similar versus dissimilar nonsensory cues. For both the similar and dissimilar nonsensory cue conditions, an equal proportion of participants preferred the first and second beverages ( similar: Proportion ${ }_{\text {first }}=50.0 \%$ vs. Proportion $_{\text {last }}=50.0 \%$; 


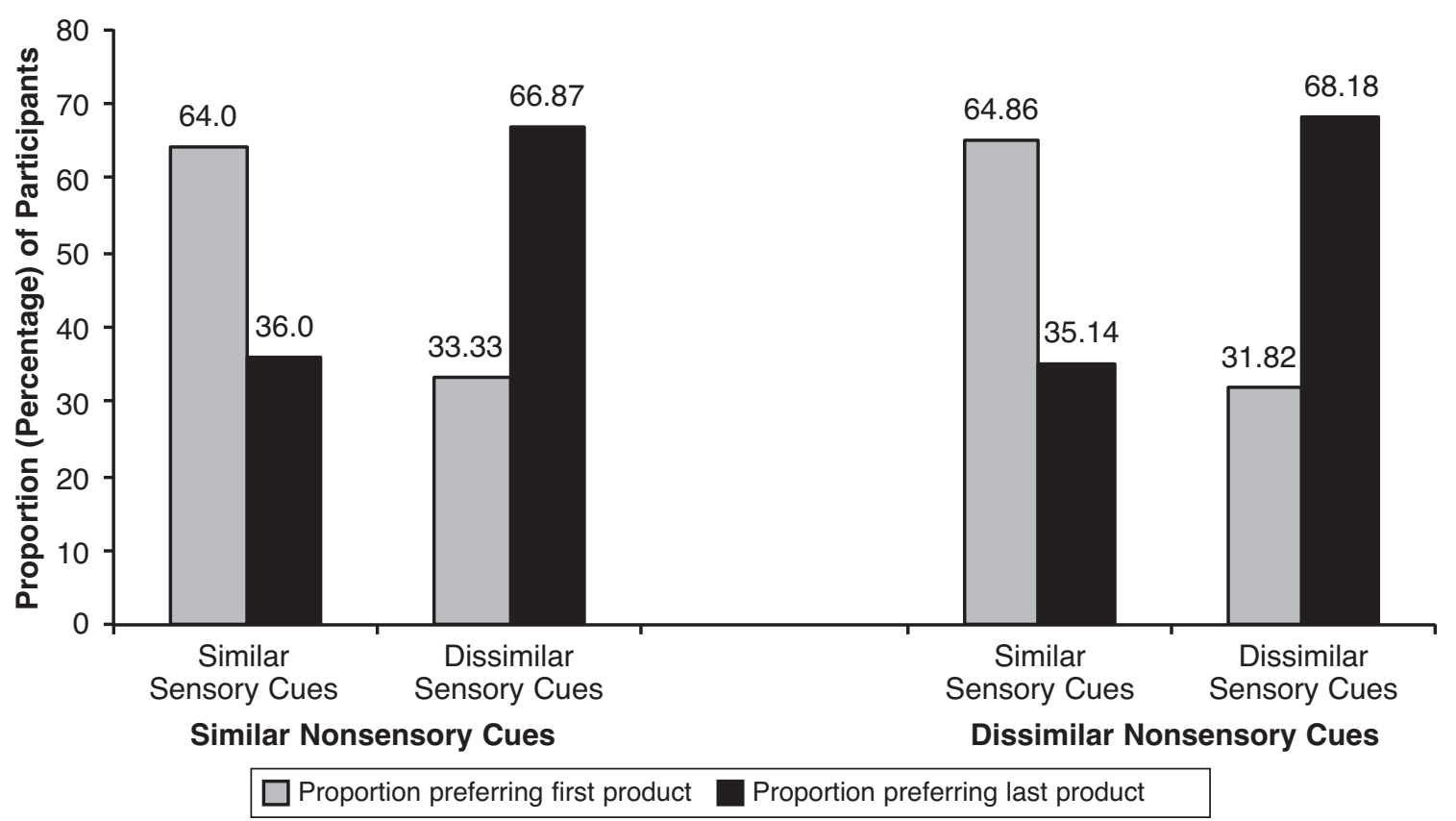

$\chi^{2}=0, p=1.0$; dissimilar: Proportion ${ }_{\text {first }}=46.91 \%$ vs. Proportion $\left._{\text {last }}=53.09 \% ; \chi^{2}=.31, p=.58\right)$. Overall, the preference pattern did not differ for similar versus dissimilar nonsensory cues $\left(\chi^{2}=.16, p=.69\right)$. These results support $\mathrm{H}_{2}$.

\section{Discussion}

The results of Study 2 again showed that when sampling two products (beverages) with similar sensory cues, consumers preferred the first product in the sequence, and when sampling two products with dissimilar sensory cues, consumers preferred the last product, regardless of whether the accompanying nonsensory cue was similar or dissimilar. Moreover, we did not observe primacy or recency effects in the context of nonsensory cue (dis)similarity. These findings provide some evidence that effects related to sensory habituation and sensory trace fading hold for sensory but not nonsensory cues. These results are also conceptually consistent with findings of prior studies in different domains that report, for example, higher variety seeking for sensory versus nonsensory attributes (Inman 2001). Next, in Study 3 , we attempt to provide more direct evidence regarding the role of sensory habituation and sensory trace fading by examining the role of sensory interruption.

\section{Study 3: Effects of Sensory Interruption}

We theorize that two opposing effects occur when people construct preferences after sampling a sequence of sensoryrich products, and the level of similarity between the sensory cues of the sampled products will influence the relative dominance of each of these effects (sensory habituation vs. sensory trace fading). Specifically, we propose that when sampling a sequence of products with similar sensory cues, the dominance of sensory habituation will create greater preference for the first sampled product. In contrast, when the sampled products have dissimilar sensory cues, sensory trace fading will lead to greater preference for the product sampled last. In Study 3, we examine whether sensory interruption during the sampling sequence weakens the effects of sensory habituation. Sensory interruption between two sensory-rich stimuli clears the trace of the earlier sensory cue and enhances the sensitivity of the later sensory cue. For example, research has shown that smelling coffee beans between smelling different fragrances acts as a form of sensory interruption because the coffee bean smelling task presumably cleanses the nasal palate after each fragrance evaluation (Cleary et al. 2010; Secundo and Sobel 2006).

In Studies 1a-2, participants sampled the sensory-rich products without interruption between each product sampling. Study 3 examines whether having consumers smell a cup of coffee beans during a sequence of sampled scent strips changes the pattern of results observed thus far. That is, suppose that a consumer smells one scented strip, smells a cup of coffee beans, and then smells the second scented strip, with both the strips being of the same color but with either similar or dissimilar fragrance scents. Will the consumer's preference be different for this sequence than when, instead of the coffee beans, he or she smells unscented cotton balls? Moreover, will either of these sequences lead to different preference patterns than what we have observed in our previous studies? Note that smelling coffee beans between evaluating scented strips has strong practical relevance because many stores offer consumers the opportunity to do so between sampling of scented strips (Veramendi, Herencia, and Ares 2013). 
As noted previously, when evaluating products on olfactory aspects, from a conceptual standpoint, there will be primacy effects (resulting from sensory habituation) as well as recency effects (resulting from subsequent experiences fading sensory traces). Having consumers smell coffee beans between scent evaluations acts as an interruption to the sensory habituation process. That is, smelling coffee or coffee beans reduces sensory habituation (Secundo and Sobel 2006). If our conceptualization related to sensory habituation is correct, having participants smell coffee beans between two olfactory-related products (e.g., scented strips) should reduce primacy effects for products with similar sensory cues. In other words, there should be a tendency for recency effects for sequentially sampled products regardless of sensory (dis)similarity when there is sensory interruption in the sequence. Thus, we propose the following:

$\mathrm{H}_{3}$ : In the presence of a sensory interruption, when sampling a sequence of sensory-rich products, consumers will prefer the last product sampled (recency effect) regardless of the level of similarity between the sensory cues of the sampled products.

\section{Design, Participants, and Procedure}

We tested $\mathrm{H}_{3}$ using a 2 (sequentially sampled products: similar vs. dissimilar) $\times 2$ (sensory interruption: absent vs present) between-subjects design experiment. One hundred eight students from a major U.S. university $\left(\mathrm{M}_{\mathrm{age}}=22\right.$ years; $52 \%$ female) participated in exchange for course credit. Study 3 used the same set of (dis)similar scents as Study 1c. However, whereas Study 1c varied the colors of the scented strips, we kept the color of the strips constant in Study 3 (white). Thus, in the dissimilar condition, we varied only the sensory cue of olfaction (fragrance). For the second factor, participants were asked to smell a cup of coffee beans (sensory interruption present condition) or a cup of unscented cotton balls (sensory interruption absent condition). In terms of procedure, after participants arrived at the lab, they were seated at a table with two white-colored scent strips (similar vs. dissimilar scents) in Ziploc bags and a cup filled with either coffee beans or cotton balls. For the similar sensory cue condition, we used two variations of lavender scent, whereas for the dissimilar sensory cue condition, we used lavender and jasmine scents. Participants were asked to sniff the first scented strip, then the contents of the cup (containing coffee beans or cotton balls), followed by the second scented strip. We counterbalanced the order of strips. The key dependent variables were similar to those used in our previous studies.

\section{Results}

Manipulation check. As we expected, participants in the dissimilar (vs. similar) sensory cue condition perceived a greater difference between the scents $\left(\mathrm{M}_{\text {dissimilar }}=4.47\right.$ vs. $\left.\mathrm{M}_{\text {similar }}=2.58 ; \mathrm{F}(1,106)=43.56, p<.01\right)$. Thus, we consider our manipulation successful.

Main test. The exact strips were counterbalanced, and there were no effects of counterbalancing across all conditions (all $\chi^{2}$ values $<.80$, and all $p$-values $>.35$ ). The results of a logistic regression showed an interaction effect between sensory cues (similar vs. dissimilar) of the sequentially sampled products and sensory interruption (absent vs. present) on product preference (Wald $\left.\chi^{2}=3.46, p<.07\right)$. As we predicted, in the absence of sensory interruption (i.e., smelling the unscented cotton balls), when sampling two similar scents, a greater proportion of participants preferred the first option in the sequence (Proportion $_{\text {first }}=71.43 \%$ vs. Proportion $\left._{\text {last }}=28.57 \% ; \chi^{2}=5.14, p<.05\right)$, implying primacy effects; when sampling two dissimilar scents, preference was higher for the last option in the sequence (Proportion $_{\text {first }}=30.77 \%$ vs. Proportion last $=69.23 \% ; \chi^{2}=3.85, p<$ $.05)$, implying recency effects. Furthermore, consistent with $\mathrm{H}_{3}$, in the presence of sensory interruption (i.e., smelling the coffee beans), participants preferred the last option in the sequence regardless of whether the scents were similar $\left(\right.$ Proportion $_{\text {first }}=33.33 \%$ vs. Proportion ${ }_{\text {last }}=66.67 \% ; \chi^{2}=$ $3.0, p<.10)$ or dissimilar $\left(\right.$ Proportion $_{\text {first }}=29.63 \%$ vs. Proportion $\left._{\text {last }}=70.37 \% ; \chi^{2}=4.48, p<.05\right)$. Overall, in the absence of sensory interruption, the preference pattern differed for similar (primacy effects) versus dissimilar sensory cues (recency effects) $\left(\chi^{2}=8.93, p<.01\right)$. However, there were no effects of similar versus dissimilar sensory cues on preferences in the presence of sensory interruption $\left(\chi^{2}=\right.$ $.09, p=.77)$. Figure 2 graphically presents these results.

\section{Discussion}

The results of Study 3 provide additional evidence regarding our proposed theorization. Consistent with our previous studies, consumers sampling a sequence of products with similar (dissimilar) sensory cues preferred the first (last) option in the absence of sensory interruption; however, the pattern of effects changed in the presence of a sensory interruption in the sequence. That is, when consumers smelled a cup of coffee beans between smelling two sequential scented strips, they exhibited greater preference for the last option in the sequence regardless of sensory similarity. In other words, having a sensory interruption in the sequence presumably weakened the effects of sensory habituation, and thus, recency effects emerged. This finding is consistent with prior studies demonstrating weakening of sensory habituation with coffee smelling (e.g., Secundo and Sobel 2006) and provides additional evidence for our theorized effects related to sensory habituation. Note that the effects of sensory interruption are not merely an effect of a time lag between the sampled scented strips, because in the condition without sensory interruption, participants smelled a similar cup with unscented cotton balls. Although some studies have raised concerns about the usefulness of coffee beans as nasal palate cleansers when smelling a sequence of scents, several studies have demonstrated their effectiveness (Veramendi, Herencia, and Ares 2013). Next, in Study 4a, we examine scenarios related to a sequence of three products.

\section{Study 4a: Sampling a Sequence of Three Products}

Study $4 \mathrm{a}$ has two key objectives. First, we attempt to enhance the robustness of our previous studies' key findings by examining the effects of sampling from a three-product 


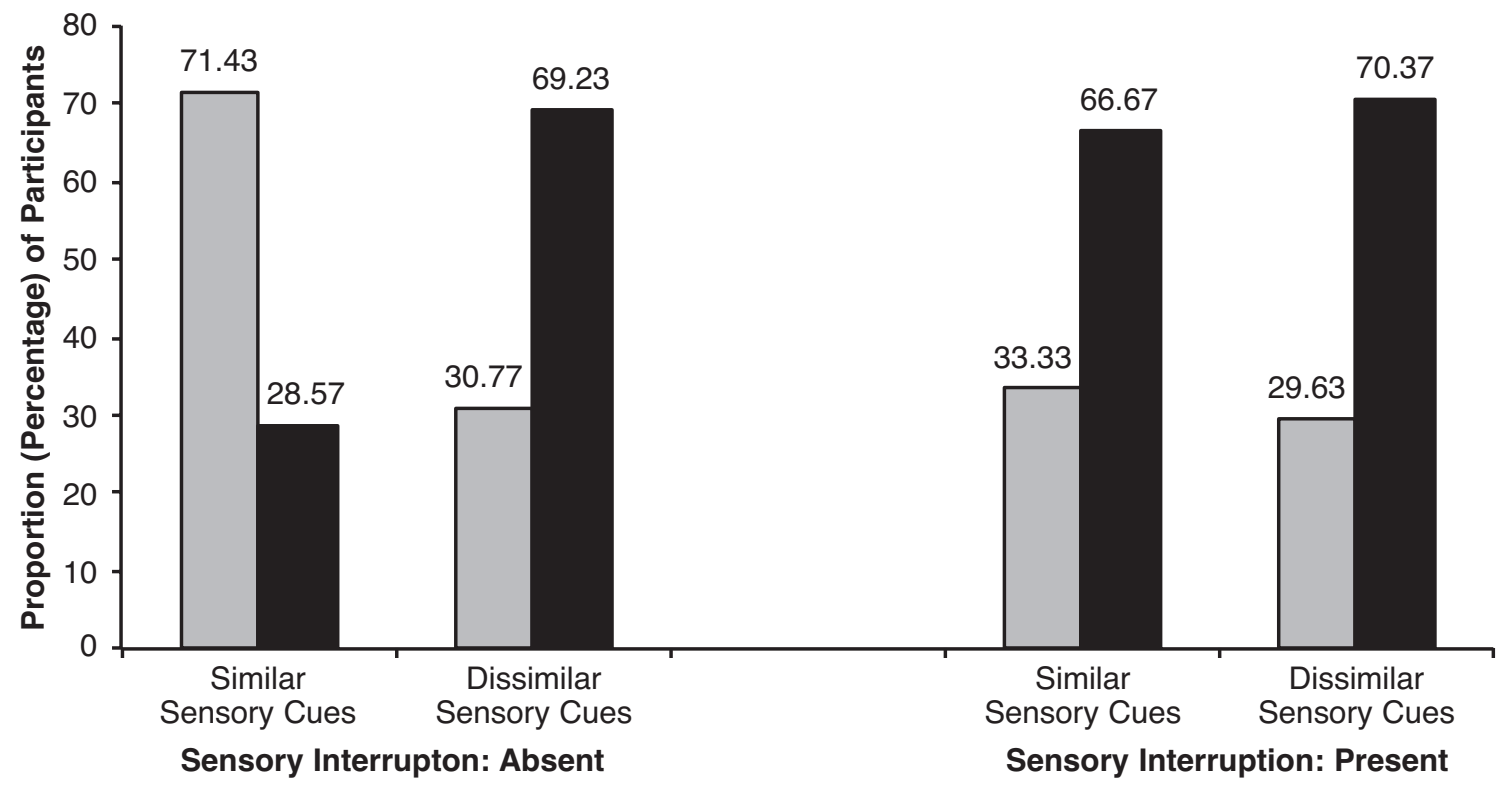

Proportion preferring first product

Proportion preferring last product

sequence and with a different set of products (recorded music clips). Second, and more importantly, we attempt to provide additional evidence regarding our theorization. Specifically, we have proposed that for a sequence of products with similar sensory cues, primacy effects will result from sensory habituation, whereas for a sequence of products with dissimilar sensory cues, recency effects will result from sensory trace fading with subsequent sensory experiences. If this theorization holds, a sequence of three products with similar sensory cues should yield greatest preference for the first sampled product, followed by the second sampled product, followed by the third sampled product. Conversely, a sequence of three products with dissimilar sensory cues should yield greatest preference for the last sampled product, followed by the second sampled product, followed by the first sampled product. We test these theoretical claims in Study 4a.

\section{Design, Participants, and Procedure}

Study 4a was a single-factor between-subjects experiment with three music clips that were either similar or dissimilar to one another (in terms of tempo, genre, and rhythm). First, we conducted a pretest $(n=40)$ to determine music clips that were similar or dissimilar to one another but had comparable favorability evaluations. We conducted both the pretest and the main experiment with a national online panel of American participants; we used foreign music clips to avoid familiarity bias.

In the pretest, we measured participants' evaluations by asking them three questions on seven-point scales related to overall rating of the music clip ( 1 = "very unpleasant," and 7 = "very pleasant"), their liking ( 1 = "hated it," and $7=$ "loved it"), and how enjoyable the music piece was $(1=$ "not at all enjoyable," and 7 = "very enjoyable"). Participants completed their evaluations immediately after listening to each music clip, and there were filler tasks between each clip. Using the results of the pretest, we chose three music clips that were similar to one another and had comparable levels of evaluation ( $\mathrm{M}=4.16$ vs. $\mathrm{M}=4.13$ vs. $\mathrm{M}=$ 4.32 ; all $p$-values $>.40$ for pairwise comparisons). Similarly, we chose three music clips that were dissimilar in terms of tempo, genre, and rhythm but had comparable levels of evaluation ( $M=4.28$ vs. $M=4.06$ vs. $M=4.36$; all $p$-values $>.30$ for pairwise comparisons). Overall, all the six clips had the same level of favorable evaluations (all $p$ values $>.30$ ). The three similar music clips were salsa/Latin musical pieces, all of which had between 93 and 96 beats per minute (tempo), and the three dissimilar music clips were instrumental pieces that ranged widely in their tempo, instrument use (classical instruments vs. synthesizer), and overall genre.

Seventy-three respondents $\left(\mathrm{M}_{\mathrm{age}}=32\right.$ years; $33 \%$ female) from a national online panel of people residing in the United States participated in exchange for monetary compensation. Participants completed the study on a computer on which they first listened to a sequence of three 25second music clips that were either similar or dissimilar. The website software (Qualtrics) randomized the sequence in which the participants listened to each music clip. Afterward, participants responded to a series of questions, including the key dependent variable of product preference ("Between the three music clips that you heard, which one did you like the most?") and a manipulation check question related to perceived (dis)similarity between the three music clips. 


\section{Results}

Manipulation check. As we expected, participants in the dissimilar (vs. similar) music condition perceived greater dissimilarity between the music clips $\left(\mathrm{M}_{\text {dissimilarity }}=4.77\right.$ vs. $\left.\mathrm{M}_{\text {similarity }}=2.74 ; \mathrm{F}(1,71)=31.58, p<.01\right)$. Thus, we conclude that our manipulation was successful.

Main test. Overall, the preference patterns were different for the similar versus dissimilar music clip conditions, with primacy effects for similar music clips and recency effects for dissimilar music clips $\left(\chi^{2}=30.03, p<.01\right)$. Consistent with our theorization about the effects of sensory habituation, when sampling the three similar music clips, participants exhibited the greatest preference for the first music clip, followed by the second and third clips (Proportion $_{\text {first }}=60.53 \%$ vs. Proportion second $=28.95 \%$ vs. Proportion $\left._{\text {third }}=10.52 \% ; \chi^{2}=14.58, p<.01\right)$. Preference for the first sampled product was statistically greater than that for the second sampled product $\left(\chi^{2}=4.24, p<.05\right)$, and preference for the second sampled product was in turn greater than that for the third sampled product $\left(\chi^{2}=3.27, p<.08\right)$. In contrast, and consistent with theorizing related to sensory trace fading effects, when sampling the three dissimilar music clips, participants exhibited the greatest preference for the third music clip, followed by the second and first clips (Proportion $_{\text {third }}=62.86 \%$ vs. Proportion ${ }_{\text {second }}=$ $31.43 \%$ vs. Proportion ${ }_{\text {first }}=5.71 \% ; \chi^{2}=17.20, p<.01$ ). Follow-up tests show that the preference for the third sampled product was statistically greater than that for the second sampled product $\left(\chi^{2}=3.67, p<.06\right)$, and the preference for the second sampled product was in turn greater than that for the first sampled product $\left(\chi^{2}=6.23, p<.05\right)$. Figure 3 graphically presents these findings.

\section{FIGURE 3}

\section{Study 4a: Sampling Sequence of Three Products}

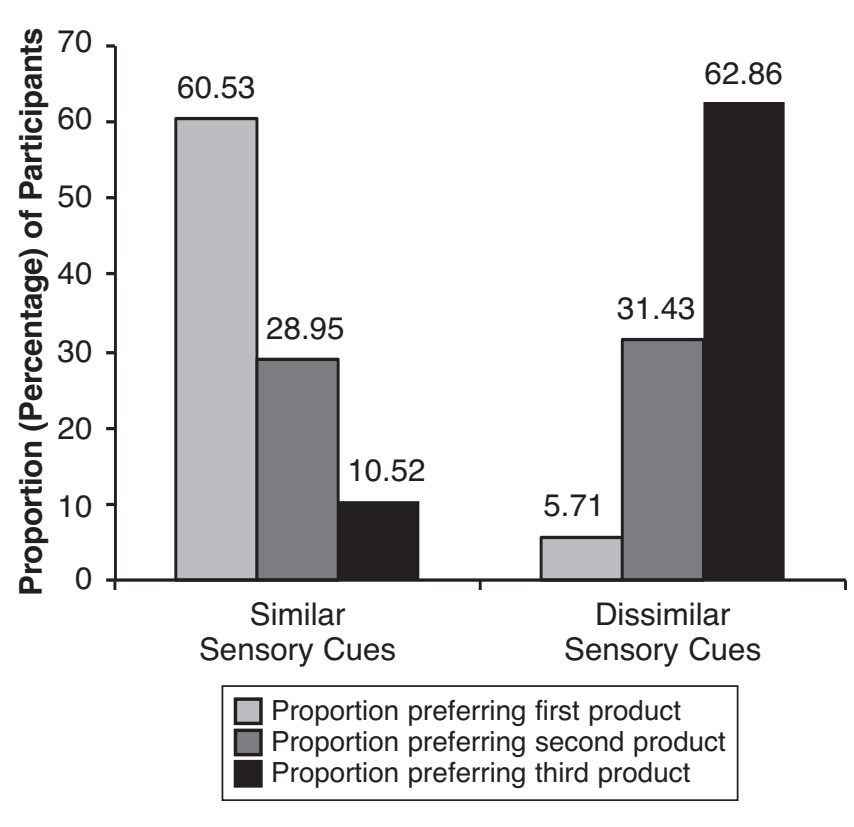

\section{Discussion}

The results of Study 4a provide further evidence for our theorization. Consistent with the proposed effects of sensory habituation, there is a declining rate of preference for the sampled products from the first through the third when the sensory cues are similar. In contrast, and consistent with our theorizing related to sensory trace fading with subsequent sensory experiences, participants showed strongest preference for the third sampled products, with declining rates of preference for the second and first sampled products when the products have dissimilar sensory cues. Study $4 \mathrm{~b}$ examines the effects of providing an indifference option.

\section{Study 4b: Effects of an Indifferent Option}

Studies 1a-4a involve forced choice scenarios, wherein participants did not have the choice to be indifferent to the options. In contrast, in Study 4b, we attempt to enhance the robustness of our findings by examining the effects of providing an indifference option. That is, when asked about their preference for the item they liked most, participants were given the option of being indifferent to the two sequentially sampled products.

\section{Design, Participants, and Procedure}

Study $4 b$ 's design is similar to Studies $1 \mathrm{a}$ and $1 \mathrm{~b}$ and uses similar products to those of Study $4 \mathrm{a}$. That is, Study $4 \mathrm{~b}$ is a single-factor between-subjects experiment with two music clips that were either similar or dissimilar to each other (in terms of tempo, genre, and rhythm). We selected the two similar and dissimilar music clip pairs from the mix used in Study $4 \mathrm{a}$ using the same pretest. Specifically, we chose two music clips that were very similar to each other and had comparable evaluations $(\mathrm{M}=4.16$ vs. $\mathrm{M}=4.13 ; \mathrm{F}(1,39)=$ $.03, p=.86)$ and then two music clips that were dissimilar in terms of tempo, genre, and rhythm but had comparable evaluations $(\mathrm{M}=4.28$ vs. $\mathrm{M}=4.06 ; \mathrm{F}(1,39)=.54, p=.47)$. In essence, the four clips had the same level of favorable evaluation (all $p$-values $>.40$ ).

One hundred eighteen students from a major U.S. university $\left(\mathrm{M}_{\text {age }}=23\right.$ years; $51 \%$ female $)$ participated in exchange for course credit. Participants completed the study on a computer on which they first listened to the two 25 -second music clips that were either similar or dissimilar. We counterbalanced the sequence in which the participants listened to each music clip to ensure that the serial position of a particular music clip did not bias the outcomes. There were no effects of counterbalancing on preferences for the similar music clips $\left(\chi^{2}=1.66, p=.44\right)$ or the dissimilar music clips $\left(\chi^{2}=1.15, p=.56\right)$. Participants responded to a series of questions, including product preference ("Between the two music clips that you heard, which one did you like more?") and perceived similarity/dissimilarity between the music clips (the manipulation check). The product preference measure was phrased the same way as in our previous studies, except that participants were allowed to select the option of being indifferent (equal preference) to the two sampled music clips. 


\section{Results}

Manipulation check. Consistent with the manipulations, participants in the sensory-dissimilarity (vs. sensorysimilarity) condition perceived greater dissimilarity between the music clips $\left(\mathrm{M}_{\text {dissimilarity }}=5.20 \mathrm{vs}\right.$. $\mathrm{M}_{\text {similarity }}=$ $3.44 ; \mathrm{F}(1,116)=35.54, p<.01)$. Thus, we conclude that our manipulation was successful.

Main test. Introducing an indifference option did not change the pattern of results. Consistent with our hypothesis $\left(\mathrm{H}_{1}\right)$ and the findings of our previous studies, we found primacy effects for the similar music clips and recency effects for the dissimilar music clips $\left(\chi^{2}=21.95, p<.01\right)$. Specifically, for the two similar music clips, there was greater preference for the first music clip Proportion $_{\text {first }}=$ $62.96 \%$ vs. Proportion ${ }_{\text {last }}=22.22 \%$, with $14.82 \%$ choosing the indifference option; $\chi^{2}=21.78, p<.01$ ). Follow-up tests show that the preference for the first clip was greater than for the last clip $\left(\chi^{2}=10.52, p<.01\right)$. In contrast, for the dissimilar music clips, participants had greatest preference for the last music clip (Proportion ${ }_{\text {first }}=35.94 \%$ vs. Proportion $_{\text {last }}=62.50 \%$, with $1.56 \%$ choosing the indifference option; $\left.\chi^{2}=35.84, p<.01\right)$. Follow-up tests show that the preference for the last clip was greater than for the first $\operatorname{clip}\left(\chi^{2}=4.59, p<.05\right)$.

\section{Discussion}

The findings of Study $4 \mathrm{~b}$ enhance the robustness of our findings. Even when participants were given the choice to be indifferent to the options, the pattern of results remains the same as that observed in our previous studies.

\section{General Discussion}

\section{Summary and Conclusions}

The results of seven experimental studies-conducted across diverse settings and groups of consumers (through field experiments, through lab studies, and with online panels of participants) and using different types of products (fragrances, beverages, chocolates, and music) - show that sequential sampling of sensory-rich products and the degree of (dis)similarity between the sensory cues (related to visual, olfactory, gustatory, and auditory aspects) of the sampled products influences consumer choices. Specifically, when sampling products with similar sensory cues, there are primacy effects leading to higher preference for the first sampled product. In contrast, when sampling products with dissimilar sensory cues, there are recency effects, whereby there is greater preference for the last sampled product.

Two contrasting theoretical effects occur when sampling sensory-rich products. The theory of sensory habituation (Morewedge, Huh, and Vosgerau 2010) predicts decreasing sensitization or reduced liking for products in a sequence, whereby the sensory-rich product sampled first in a sequence will be liked relatively more than products sampled sequentially later. Therefore, sensory habituation predicts primacy effects (i.e., preference for the first product in a sequence). In contrast, the theory of sensory trace fading
(Zylberberg et al. 2009) predicts that the experience associated with a sequentially earlier sensory experience will fade with additional sensory experiences. Thus, sensory trace fading theory will predict recency effects, whereby consumers will exhibit greater preference for the product sampled last. We hypothesized that effects related to sensory habituation will be more dominant when sampling a sequence of products with similar sensory cues, whereas sensory trace fading will be more dominant when sampling a sequence of products with dissimilar sensory cues. The results of our experiments support the proposed effects and also provide evidence for the posited theoretical model.

We also found some direct evidence for the proposed underlying process. For example, in Study 3, smelling coffee beans between sampling scent strips diminished the sensory experience traces associated with the first sampled scent because smelling coffee beans perceptually cleanses the nasal palate (Cleary et al. 2010; Secundo and Sobel 2006). As a result, the presence of a sensory interruption led to recency effects in terms of preference for the last sampled product. Notably, in addition to providing process evidence, sensory interruption is a managerially relevant moderator. The results of Study 4a provide additional evidence for our theorization by examining three-product sequences. The results show that the preference pattern is ordinal. That is, for the three products with similar sensory cues, participants had the greatest preference for the first sampled product, followed by the second, and then the last, in diminishing order of magnitude. Conversely, for the products with dissimilar sensory cues, participants had the greatest preference for the last sampled product, followed by the second, and then the first. This pattern is consistent with the sensory habituation effects predicted for similar sensory cues and sensory trace fading effects for dissimilar sensory cues.

Marketers often use product sampling as an effective promotional tool (Notte 2011; Wadhwa, Shiv, and Nowlis 2008). Despite its prevalence, there has been limited focus on effects of sampling in the marketing literature, with prior studies examining such factors as effects of distraction while sampling products (Nowlis and Shiv 2005; Shiv and Nowlis 2004) and how the sampling of a consumption cue with high incentive value might enhance subsequent consumption of other products (Wadhwa, Shiv, and Nowlis 2008). However, from a conceptual perspective, to the best of our knowledge, this is the first study to examine the effects of sampling products with similar versus dissimilar sensory cues on product choices. Along these lines, ours is the first research to examine how sensory habituation and sensory trace fading effects influence preferences for sequentially sampled products with different types of sensory cues.

These findings also have implications for the literature stream on product sequences and order effects in general. Most prior studies on order effects have examined nonsensory cues and attributes (e.g., brand name, price discounts, warranties) and have typically focused on outcomes related to judgments (e.g., product evaluations). The present research's focus on sensory cues, actual experiential consumption/sampling, and choices/preferences has both conceptual and managerial implications. Specifically, from a 
conceptual perspective, the findings provide insights into consumer choice processes when sampling multiple products with similar versus dissimilar sensory cues. Although there is extant research on how consumer choices are constructed, no study to date has investigated the particular set of sensory-related variables examined in this research. Our findings also provide an understanding of how consumers make choices when there are contrasting effects, such as through sensory habituation and sensory trace fading. Moreover, although there is emerging research in the domain of sensory marketing (Krishna 2012), no study has examined how (dis)similarity of sensory cues can influence choices while sampling products in a sequence. Thus, our findings contribute to a better understanding of the role of sequential sensory cues on consumer choice formation.

Another key contribution of this research is that it reconciles differences in research findings on order effects in the context of choices/preferences for sensory-rich experiential products. The results show that when sampling sequential products with similar sensory cues, there are primacy effects, but when sampling sequential products with dissimilar sensory cues, there are recency effects. In the context of these findings, it is not surprising that Mantonakis et al. (2009) report primacy effects, especially for shorter sequences, when participants in their experiment sampled a sequence of wines, whereas Biswas, Grewal, and Roggeveen (2010) report recency effects when participants in their experiment sampled a sequence of flavored beverages. O'Brien and Ellsworth (2012) also report results consistent with recency effects for their experiment when participants sampled a sequence of chocolates. In the experiment conducted by Mantonakis et al. (2009), participants were not consciously made aware that the same wine was presented multiple times in a sequence. However, on the basis of our findings, we propose that sensory habituation may have had a dominating effect in Mantonakis et al.'s study because the products had similar sensory cues, and therefore, they observed primacy effects. An earlier study by Dean (1980) also notes primacy effects. Although Dean provides no specific details regarding the types of stimuli (i.e., specific type of food or beverage) used in his experiment, he does refer to a "palate desensitization" effect (p. 109) while speculating about the reasons behind the effects he observed. So in essence, sensory habituation, which would also lead to "palate desensitization," is likely to have played a role in his experiment and is consistent with the effects we observed when participants sampled products with similar sensory cues. ${ }^{1}$ In contrast, in Biswas, Grewal, and Roggeveen's (2010) experiment, the beverages in the sequence had different flavors. Along the same lines, in O'Brien and Ellsworth's (2012) experiment, participants

${ }^{1}$ However, note that Dean's (1980) participants were between 13 and 49 years of age, implying the presence of participants below 18 years, whereas the other three studies mentioned (Biswas, Grewal, and Roggeveen 2010; Mantonakis et al. 2009; O'Brien and Ellsworth 2012) used adult (at least 18 years of age) participants only. Therefore, care should be taken when comparing the findings of Dean's study with those of the other three studies or the present study. sampled a sequence of five chocolates, each with a different flavor (milk, dark, crème, caramel, and almond) ${ }^{2}$ In the context of our research, we propose that because of dissimilar sensory cues, sensory trace fading effects were more dominant for Biswas, Grewal, and Roggeveen (2010) and O'Brien and Ellsworth (2012), and therefore, they observed recency effects. Although the findings of previous studies on order effects involving choices for sensory-rich products might seem contradictory at first glance, the contradiction can be resolved in the light of our findings.

Notably, in Study 2, we found that changing the color of the scent strips had an effect on scent preferences even though the scent strip was not an integral part of the fragrance. This finding ties in with emerging research studies on cross-modal sensory effects, which have demonstrated that visual cues can influence olfactory perceptions (Hanson-Vaux, Crisinel, and Spence 2013). The findings of Study 1c in the current research show that such a cross-modal effect can also influence product choices in a sequence. Additional research is needed to examine this cross-modal effect in further depth.

Our research differs from prior research that has examined the order effects of encountering a sequence of experiential and informational stimuli (e.g., Lee, Frederick, and Ariely 2006; Wilcox, Roggeveen, and Grewal 2011). For example, Lee, Frederick, and Ariely (2006) find that consumer evaluations of beer were more strongly affected when the informational stimuli were presented before tasting the beer. Wilcox, Roggeveen, and Grewal (2011) find a similar pattern of results with different product categories (e.g., chocolate, wine). In contrast, in our research, no informational stimuli were given to the participants (except in the study in which we examined the effects of brand information); instead, participants constructed choices only through actual experiential sampling/consumption of the products.

\section{Managerial and Regulatory Implications}

Because practitioners have vested interests in understanding how product sampling influences consumer behavior (Hein 2009; Tuttle 2011), it is pertinent to have a better understanding of how consumers make decisions when sequentially sampling products with similar versus dissimilar sensory cues and how these effects influence purchase behavior. This topic is especially relevant because marketers can often control the order and types of samples in a sequence. The more than $\$ 1$ billion that the food and beverage industry spends annually on product sampling is evidence of its importance (Horovitz 2011). Product samplings come in different forms and often involve products with strong sensory cues. For example, in 2012, department store fragrances generated more than $\$ 500$ million in sales, and fragrance sampling through scent strips in stores and magazine inserts played an influential role in generating these sales. Indeed, $12 \%$ of a fragrance's price is devoted to marketing and packaging, and companies consider the role of scent

${ }^{2}$ We obtained details regarding the stimuli used in these three studies (Biswas, Grewal, and Roggeveen 2010; Mantonakis et al. 2009; O'Brien and Ellsworth 2012) from the information provided in the respective articles and/or through personal correspondence with the respective lead authors. 
strips an important factor in this budget (Thau 2012). Similarly, stores such as Costco and other supermarkets frequently provide food samples to consumers and observe positive outcomes (Notte 2011) and repeat purchase behavior (Hein 2009). Several research studies have also noted both short-term and long-term positive effects of free product sampling (Pauwels and Weiss 2008).

Moreover, retailers such as Saks Fifth Avenue and others provide consumers with multiple fragrance samples in addition to scent strip samples (Louis 2011). Free product samples not only enhance the overall shopping experience but also directly translate into sales. Indeed, managers have recently begun to emphasize how availability of product sampling can be correlated with product sales and have even attributed the decreased sales of fragrances in 2012 to restrictive sampling policies (IRI 2013). Given retailers' increasing emphasis on allowing consumers to sample multiple products, such as scent strips (Louis 2011), our findings have strong managerial implications. Specifically, fragrance companies and retailers have considerable flexibility in determining the color of the scent strips as well as the display pattern of the fragrances. For example, whereas Sephora usually uses the same white scent strip for all its fragrance samples, Macy's tends to have different (colored/ shaped) strips for each fragrance. At the same time, fragrance companies and retailers are increasingly emphasizing multiple sampling opportunities for consumers (Louis 2011). As the results of our studies show, the color of the scent strips and the (dis)similarity in the smell of the fragrances while sampling can influence choices. In addition, sensory interruption can influence choices as well. These findings could be helpful for companies and retailers when choosing optimal display patterns and colors of scent strips and controlling the sequence in which consumers sample the fragrances.

Online stores such as iTunes and Amazon.com provide music samples before purchase. Other venues in which consumers can sample sensory-rich products include food courts at malls, where vendors often give out food samples to attract potential customers (Lillegard 2011). In almost all these contexts, retailers/vendors can usually control the sequence in which consumers experience these samples. Because retailers often give out samples to drive sales for specific products for various reasons (e.g., to increase sales for higher margin products, to cut down inventory; Notte 2011), they can strategically position their product samples to influence the sequential order in which consumers experience them.

The wine industry is another product category highly dependent on product sampling. Sampling is a major success factor for this industry, as reflected by the finding that a high proportion of wine sales occur in tasting rooms
(Gomez 2010), and wine tasting events can translate into significant increase in sales (Lockshin and Knott 2009). Wines are not sampled in isolation. Often, the sampled wines are similar (e.g., both wines are made with the Merlot grape varietal) or dissimilar (e.g., one wine is Merlot and the other is Cabernet Sauvignon). Sommeliers (i.e., wine stewards) typically choose the sampling order of wines (DeMarchi 2012) and can strategically set the sequence of wine sampling, which in turn can influence choices. This can be extended to other areas, including event planning (i.e., selecting the presentation order for food, beverage, and other sensory rich elements).

At a broader level, managers are increasingly focusing on sensory and experiential aspects of marketing (WyrleyBirch 2013). As mentioned previously, managers have even focused on sounds made by deodorant sprays, in addition to other sensory cues, such as the smells, tastes, and colors associated with products (Hall 2013). However, from prior research, it is unclear how different combinations of sensory cues might influence consumer choices in retail settings, especially when consumers can sample these products. Our research provides insights into how sensory cues associated with sequentially sampled products can influence choices.

\section{Limitations and Future Research Directions}

We proposed that both sensory habituation and sensory trace effects can influence preferences when sampling sensoryrich products. The results of our studies provide support for our theorizing. However, we did not undertake formal tests of mediation for the underlying process. In addition, assimilation and contrast effects can offer alternative process explanations (see, e.g., Bless and Schwarz 2010; Chernev 2011). Further research should examine the underlying process in greater depth and rule out potential alternative explanations for the findings.

Across our studies, the products sampled by the consumers had either similar or dissimilar sensory cues. It might be worthwhile to examine the order effects when consumers sequentially sample a mix of similar and dissimilar sensory cues. The present research could also be extended by examining the roles of relevant moderators such as involvement or experience with the product or personality traits of the consumer (see, e.g., Argo and White 2012). Finally, we focused on product choices. Further research should examine the sequential effects of sampling products with similar versus dissimilar sensory cues on other dependent variables, such as purchase intentions, willingness to pay, and word-of-mouth activity. We hope that our research will encourage work in these and related areas.

\section{REFERENCES}

Argo, Jennifer J. and Katherine White (2012), "When Do Consumers Eat More? The Role of Appearance Self-Esteem and Food Packaging Cues," Journal of Marketing, 76 (March), 67-80.

Avena, Nicole M. and Mark S. Gold (2011), "Variety and Hyperpalatability: Are They Promoting Addictive Overeating?" American Journal of Clinical Nutrition, 94 (2), 367-68.
Biswas, Dipayan, Abhijit Biswas, and Subimal Chatterjee (2009), "Making Judgments in a Two-Sequence Cue Environment: The Effects of Differential Cue Strengths, Order Sequence, and Distraction," Journal of Consumer Psychology, 19 (1), 88-96. _ Dhruv Grewal, and Anne Roggeveen (2010), "How the Order of Sampled Experiential Products Affects Choice," Journal of Marketing Research, 47 (June), 508-519. 
_ Guangzhi Zhao, and Donald R. Lehmann (2011), "The Impact of Sequential Data on Consumer Confidence in Relative Judgments," Journal of Consumer Research, 37 (5), 874-87.

Bless, Herbert and Norbert Schwarz (2010), "Mental Construal and the Emergence of Assimilation and Contrast Effects: The Inclusion/Exclusion Model," in Advances in Experimental Social Psychology, Vol. 42, James M. Olson and Mark P. Zanna, eds. Amsterdam: Elsevier, 319-73.

Büyükkurt, B. Kemal (1986), "Integration of Serially Sampled Price Information: Modeling and Some Findings," Journal of Consumer Research, 13 (3), 357-73.

Chernev, Alexander (2011), "Semantic Anchoring in Sequential Evaluations of Vices and Virtues," Journal of Consumer Research, 37 (5), 761-74.

Cleary, Anne M., Kristen E. Konkel, Jason S. Nomi, and David P. McCabe (2010), "Odor Recognition Without Identification," Memory \& Cognition, 38 (4), 452-60.

Dean, Michael L. (1980), "Presentation Order Effects in Product Taste Tests," Journal of Psychology, 105 (1), 107-110.

DeMarchi, Stefano (2012), "A Mathematical View of Matching Food and Wine," International Journal of Contemporary Mathematical Sciences, 7 (33), 1639-52.

Driver, Jon and Toemme Noesselt (2008), "Multisensory Interplay Reveals Crossmodal Influences on 'Sensory-Specific' Brain Regions, Neural Responses, and Judgments," Neuron, 57 (1), 11-23.

Elberse, Anita (2010), "Bye-Bye Bundles: The Unbundling of Music in Digital Channels," Journal of Marketing, 74 (May), 107-123.

Elder, Ryan S. and Aradhna Krishna (2010), "The Effects of Advertising Copy on Sensory Thoughts and Perceived Taste," Journal of Consumer Research, 36 (5), 748-56.

Engel, Tatiana and David Andrieux (2010), "Forget Before You Remember: Dynamic Mechanism of Memory Decay and Retrieval," Frontiers in Neuroscience, 4 (1), 3-5.

Epstein, Leonard H., Jennifer L. Temple, James N. Roemmich, and Mark E. Bouton (2009), "Habituation as a Determinant of Human Food Intake," Psychological Review, 116 (2), 384-407.

Gomez, Miguel (2010), "Increasing Customer Satisfaction Improves Tasting Room Sales," Research Focus 2010-3: Cornell Viticulture and Enology, (accessed October 4, 2013), [available at http://grapesandwine.cals .cornell.edu/cals/grapesandwine/ appellation-cornell/issue-4/loader.cfm?csModule=security/ getfile\&PageID=938365].

Graziano, Martin and Mariano Sigman (2008), "The Dynamics of Sensory Buffers: Geometric, Spatial, and Experience-Dependent Shaping of Iconic Memory," Journal of Vision, 8 (5), 1-13.

Gürhan-Canli, Zeynep (2003), "The Effect of Expected Variability of Product Quality and Attribute Uniqueness on Family Brand Evaluations," Journal of Consumer Research, 30 (1), 105-114.

Hall, Emma (2013), "How Courvoisier and Unilever Manipulate the Senses," Ad Age, (March 19), (accessed October 4, 2013), [available at http://adage.com/article/global-news/courvoisierunilever-manipulate-senses/240426].

Hanson-Vaux, Grant, Anne-Sylvie Crisinel, and Charles Spence (2013), "Smelling Shapes: Crossmodal Correspondences Between Odors and Shapes," Chemical Senses, 38 (2), 161-66.

Havermans, Remco C., Nicolette Siep, and Anita Jansen (2010), "Sensory-Specific Satiety Is Impervious to the Tasting of Other Foods with Its Assessment," Appetite, 55 (2), 196-200.

Hein, Kenneth (2009), "Sampling Inspires Repeat Purchase," Adweek, (August 4), (accessed October 4, 2013), [available at www.adweek.com/news/advertising-branding/sampling-inspiresrepeat-purchases-99961].

Hoegg, JoAndrea and Joseph W. Alba (2007), "Taste Perception: More Than Meets the Tongue," Journal of Consumer Research, 33 (4), 490-98.
Horovitz, Bruce (2011), "New Sampling Machine Can Gauge Your Age and Sex," USA Today, (December 4), (accessed October 4, 2013), [available at http://usatoday30.usatoday. com/money/industries/food/story/2011-12-13/face-recognitonsampling-machine/51890500/1].

Inman, J. Jeffrey (2001), "The Role of Sensory-Specific Satiety in Attribute-Level Variety Seeking," Journal of Consumer Research, 28 (1), 105-120.

IRI (2013), "The Mass-Market Fragrance Landscape Is a Tale of Two Scenarios," (April 2), (accessed October 4, 2013), [available at http://www.iriworldwide.com/NewsEvents/IntheNews/ ctl/Details/mid/680/ItemID/1693.aspx].

Keller, Kevin and Donald R. Lehmann (2006), "Brands and Branding: Research Findings and Future Priorities," Marketing Science, 25 (6), 740-59.

Krishna, Aradhna (2012), "An Integrative Review of Sensory Marketing: Engaging the Senses to Affect Perception, Judgment, and Behavior," Journal of Consumer Psychology, 22 (3), 332-51.

Lee, Leonard, Shane Frederick, and Dan Ariely (2006), “Try It, You'll Like It: The Influence of Expectation, Consumption, and Revelation on Preferences for Beer," Psychological Science, 17 (12), 1054-58.

Lillegard, Robert (2011), "The New Food Court," QSR Magazine, (December), (accessed October 4), [available at http://www. qsrmagazine.com/reports/new-food-court].

Lockshin, Larry and David Knott (2009), "Boozing or Branding? Measuring the Effects of Free Wine Tastings at Wine Shops," International Journal of Wine Business Research, 21 (4), 312 24.

Louis, Catherine Saint (2011), "Fragrance Spritzers Hold Their Fire," The New York Times, (April 15), (accessed October 4, 2013), [available at http://www.nytimes.com/2011/04/17/ fashion/17Fragrance.html].

Lynch, John, Dipankar Chakravarti, and Anusree Mitra (1991), "Contrast Effects in Consumer Judgments: Changes in Mental Representations or in the Anchoring of Rating Scales?" Journal of Consumer Research, 18 (3), 284-97.

Malcolm, Andrew H. (1988), "Overpowering the Scent Market," The New York Times, (March 27), (accessed October 4, 2013), [http://www.nytimes.com/1988/03/27/magazine/overpoweringthe-scent-market.html].

Mantonakis, Antonia, Pauline Rodero, Isabelle Lesschaeve, and Reid Hastie (2009), "Order in Choice: Effects of Serial Position on Preferences," Psychological Science, 20 (11), 13091312 .

Meyers-Levy, Joan and Brian Sternthal (1993), "A Two-Factor Explanation of Assimilation and Contrast Effects," Journal of Marketing Research, 20 (August), 359-68.

Morewedge, Carey K., Young Eun Huh, and Joachim Vosgerau (2010), "Thought for Food: Imagined Consumption Reduces Actual Consumption, Science, 330 (6010), 1530-33.

Notte, Jason (2011), "Why Retailers Pay for Your Free Samples," The Street, (February 15), (accessed October 4, 2013), [available at http://www.thestreet.com/_yahoo/story/11008255/1/ why-retailers-pay-for-your-free-samples.html].

Nowlis, Stephen and Baba Shiv (2005), "The Influence of Consumer Distractions on the Effectiveness of Food-Sampling Programs," Journal of Marketing Research, 42 (May), 157-68.

Oberauer, Klaus and Stephan Lewandowsky (2008), "Forgetting in Immediate Serial Recall: Temporal Distinctiveness, or Interference?" Psychological Review, 115 (3), 544-76.

O'Brien, Ed and Phoebe C. Ellsworth (2012), "Saving the Last for Best: A Positivity Bias for End Experiences," Psychological Science, 23 (2), 163-65.

Pauwels, Koen and Allen Weiss (2008), "Moving from Free to Fee: How Online Firms Market to Change Their Business Model Successfully," Journal of Marketing, 72 (May), 14-31. 
Schwarz, Norbert and Herbert Bless (1992), "Constructing Reality and Its Alternatives: Assimilation and Contrast Effects in Social Judgment," in The Construction of Social Judgment, Leonard L. Martin and Abraham Tesser, eds. Hillsdale, NJ: Lawrence Erlbaum Associates, 217-45.

Secundo, Lavi and Noam Sobel (2006), "The Influence of Smelling Coffee on Olfactory Habituation," Chemical Senses, 31 (5), A52.

Sergent, Claire, Valentin Wyart, Mariana Babo-Rebelo, Laurent Cohen, Lionel Naccache, and Catherine Tallon-Baudry (2013), "Cueing Attention After the Stimulus Is Gone Can Retrospectively Trigger Conscious Perception," Current Biology, 23 (2), 150-55.

Shapiro, Stewart and Mark T. Spence (2002), "Factors Affecting Encoding, Retrieval, and Alignment of Sensory Attributes in a Memory-Based Brand Choice Task," Journal of Consumer Research, 28 (4), 603-617.

Shiv, Baba and Stephen Nowlis (2004), "Effects of Distraction While Tasting a Food Sample: The Interplay of Informational and Affective Components in Subsequent Choice," Journal of Consumer Research, 31 (3), 599-608.

Stecker, G. Christopher and Ervin R. Hafter (2009), "A Recency Effect in Sound Localizations?" Journal of the Acoustical Society of America, 125 (6), 3914-24.

Thau, Barbara (2012), "Behind the Spritz: What Really Goes into a Bottle of \$100 Perfume," DailyFinance, (May 22), (accessed October 4, 2013), [available at http://www.dailyfinance.com/ 2012/05/22/celebrity-perfume-cost-breakdown].

Thompson, Richard F. (2009), "Habituation: A History," Neurobiology of Learning and Memory, 92 (2), 127-34.

Troye, Sigurd V. and Magne Supphellen (2012), "Consumer Participation in Coproduction: 'I Made It Myself' Effects on Consumers' Sensory Perceptions and Evaluations of Outcome and Input Product," Journal of Marketing, 76 (March), 33-46.
Tuttle, Brad (2011), "The Power of Freebies: Why Companies Pay to Give Free Samples to Supermarket Customers," Time, (February 17), (accessed October 4, 2013), [available at http://business. time.com/2011/02/17/the-power-of-freebies-why-companiespay-to-give-free-samples-to-supermarket-customers].

Veramendi, Mily, Pilar Herencia, and Gaston Ares (2013), "Perfume Odor Categorization: To What Extent Trained Assessors and Consumers Agree?" Journal of Sensory Studies, 28 (1), 76-89.

Wadhwa, Monica, Baba Shiv, and Stephen M. Nowlis (2008), “A Bit to Whet the Reward Appetite: The Influence of Sampling on Reward-Seeking Behaviors," Journal of Marketing Research, 45 (August), 403-413.

Wilcox, Keith, Anne Roggeveen, and Dhruv Grewal (2011), "Shall I Tell You Now or Later? Assimilation and Contrast in the Evaluation of Experiential Products," Journal of Consumer Research, 38 (4), 763-73.

Wyrley-Birch, Michael (2013), "Experiential Marketing: Shaping the Future Face of Retail," Marketing Week, (accessed October 4, 2013), [available at http://www.marketingweek.co.uk/strategiesand-tactics/experiential-marketing-shaping-the-future-face-ofretail/4005818.article].

Yu, Dinghui, Artem Ponomarev, and Ronald L. Davis (2004), "Altered Representation of the Spatial Code for Odors After Olfactory Classical Conditioning: Memory Trace Formation by Synaptic Recruitment," Neuron, 42 (3), 437-49.

Zhu, Rui and Joan Meyers-Levy (2009), "The Influence of SelfView on Context Effects: How Display Fixtures Can Affect Product Evaluations," Journal of Marketing Research, 46 (February), 37-45.

Zylberberg, Ariel, Stanislas Dehaene, Gabriel B. Mindlin, and Mariano Sigman (2009), "Neurophysiological Bases of Exponential Sensory Decay and Top-Down Memory Retrieval: A Model," Frontiers in Computational Neuroscience, 3 (4), 1-16. 